\title{
Study on treatment of ultra-high concentration phosphorus-containing wastewater
}

\author{
Peishi Qi ${ }^{*} \quad$ Xiaoran Yao Yunzhi Liu \\ State Key Laboratory of Urban Water Resource and Environment \\ Harbin Institute of Technology \\ Harbin, China \\ qipeishi@163.com
}

\begin{abstract}
An efficient combined treatment process, limeelectrolysis was developed to treat the Ultra-high concentration phosphorus-containing Wastewater. The experimental results show that the removal rates of COD and $T P$ are $86.4 \%$, $69.9 \%$,respectively. The results indicated that the optimal conditions are: lime dosage was $2 \mathrm{~g}$, $\mathrm{pH} 8.5$, mixing rate 2.5 (equivalent units)and reaction time $20 \mathrm{~min}$, sedimentation time 10min; using the soluble iron plate and carbon rod as electrode plate, electrolysis pH 7, electric current $0.4 \mathrm{~A}$, reaction time $80 \mathrm{~min}$, exchange electrode reaction $2 \mathrm{~min}$ per $12 \mathrm{~min}$. The biodegradability of the wastewater was improved evidently. This combined process provides instructive example for efficient treatment of Ultra-high concentration phosphorus-containing Wastewater.
\end{abstract}

Index Terms - lime electrolysis Phosphorus removal

\section{INTRODUCTION}

There have been reports about treating high concentration phosphorus-containing wastewater with coagulation sedimentation, electrolysis and other technologies, some of which have been used in practical application ${ }^{[1 \circ 2]}$. However, few studies have focused on the ultra-high concentration phosphoruscontaining wastewater treatment.

Electrolysis can be used for a variety of industrial wastewater treatments ${ }^{[3-5]}$, but its application is limited by high running costs. As a traditional method for phosphorus removal, calcium lime method has advantages such as high phosphorus removal efficiency, simple operation, but there are still some problems to be solved ${ }^{[6]}$.

This study focused on treating ultra-high concentration phosphorus-containing wastewater with lime-electrolysis combined process, and investigated dosage, $\mathrm{pH}$ valueand other factors on influencing the treatment efficiency, also provided a basis for better handling of ultra-high concentration phosphoruscontaining wastewater in future.

\section{METHODS AND MATERIALS}

\section{A. Experimental water quality}

Experiment wastewater was the actual production wastewater. Water quality shown that the mass concentration of $\mathrm{TP}$ and COD are $18265 \mathrm{mg} / \mathrm{L}, 255218 \mathrm{mg} / \mathrm{L}$, respectively, $\mathrm{pH} 3.0$. B. Methods

lime method: took $50 \mathrm{ml}$ pharmaceutical wastewater in $200 \mathrm{ml}$ beaker. Regulated $\mathrm{pH}$ using $16 \mathrm{~mol} / \mathrm{L} \mathrm{NaOH}$. Beaker was placed on a magnetic stirrer after cooled, then added the lime, kept the stirrer agitating at a constand speed of 2.5 (equivalent unit), and then the beaker was standing for several minutes for settling. The reaction solution was filtered. The colature was used to measure the concentration of remaining phosphorus.

Electrolysis method: The electrolysis device was a $100 \mathrm{ml}$ electrolyzer. The size of soluble iron electrode plate was 20 $\mathrm{mm} \times 40 \mathrm{~mm} \times 1 \mathrm{~mm}$. The carbon rod electrode was $5 \mathrm{~mm}$ in diameter and $40 \mathrm{~mm}$ in length. Took $100 \mathrm{ml}$ water sample treated by cooling crystallization into the electrolyzer, regulating $\mathrm{pH}$ with dilute sulfuric acid and $\mathrm{NaOH}$, then kept the magnetic stirrer agitating at a constand speed of 1.5 (equivalent unit) to blend it well. kept the plate disdance at $3.5 \mathrm{~cm}$.

C. Analytical methods

The Phosphorus concentration were analyzed by ammonium molybdate spectro-photometry . $\mathrm{pH}$ was measured by $\mathrm{pH}$ meter.

\section{RESULTS AND DISCUSSION}

A. Results of phosphorus removal by lime

1) Effect of $\mathrm{pH}$ on phosphorus removal.

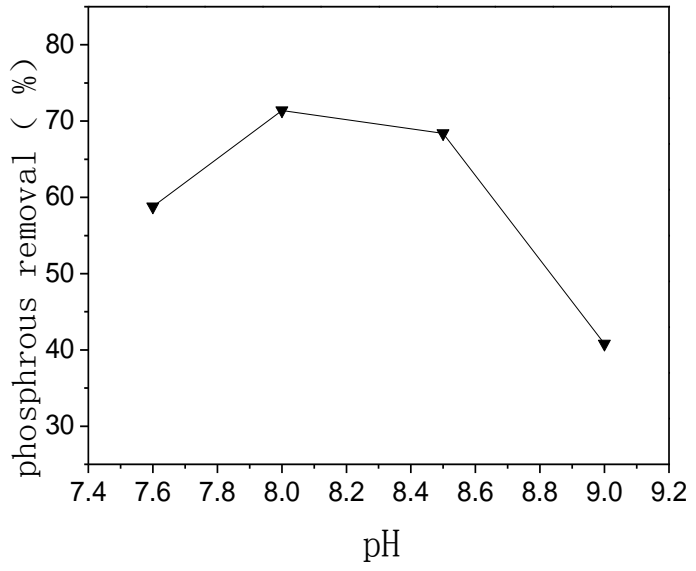

Fig.1 Effect of $\mathrm{pH}$ on phosphorus removal

With the solution alkalinity increased, phosphorus removeal rate increased from less than $45 \%$ to over $70 \%(\mathrm{pH}=8.5)$. Phosphorus removal reaction by lime was more thorough unde $r$ alkaline conditions, for the abundant presence of $\mathrm{Ca}^{2+}$ and $\mathrm{OH}^{-}$stimulated the reaction in the direction of precipitation. However, when $\mathrm{pH}$ was too high(more than 8.5), phosphorus re moval rate decreased for the reason that excessive $\mathrm{OH}$ - compete $\mathrm{d}$ with phosphate anion to combine with calcium ion, leading to 1 
ess calcium phosphate product. At the same time, sedimentatio $\mathrm{n}$ performance of the wastewater deteriorated, decreasing the ph osphorus removal rate by less phosphate precipitation.

2) Effect of dosage on phosphorus removal.



Fig. 2 Effect of different dosages on phosphorus removal

With the increase of lime dosages, phosphorus removal ra-t e was declined as a whole. The phosphorus removal rate was 71 . $4 \%$ when adding $2 \mathrm{~g}$ lime. $\mathrm{Ca}^{2+}$ and $\mathrm{PO}_{4}{ }^{3-}$ react step by step. Th e increase of $\mathrm{Ca}^{2+}$ can ensure that $\mathrm{Ca}^{2+}$ is sufficient in reaction $\mathrm{s}$ ystem, The excess $\mathrm{Ca}^{2+}$ and $\mathrm{OH}^{-}$would promote the reaction $3 \mathrm{P}$ $\mathrm{O}_{4}{ }^{3+}+5 \mathrm{Ca}^{2+}+\mathrm{OH}^{-}=\mathrm{Ca}_{5}\left(\mathrm{PO}_{4}\right)_{3} \mathrm{OH}$, which was good for getting ri $\mathrm{d}$ of PO43- in the sewage. However, too much lime led phospho rus removal rate decreased, mainly due to the interference effec $\mathrm{t}$ of ions, suspended solids and crystal Which making it difficul $\mathrm{t}$ for the combination of free $\mathrm{Ca} 2+$ and $\mathrm{P}$.

\section{3) Effect of reaction time on phosphorus removal.}

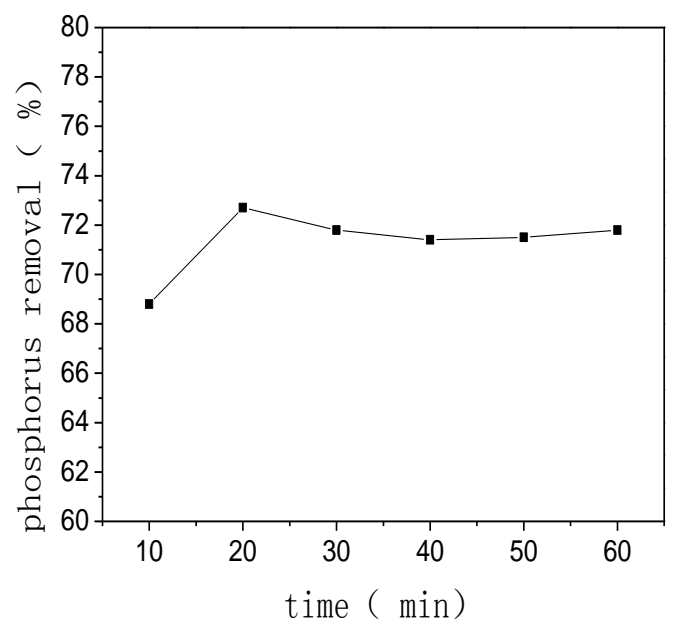

Fig .3 Effect of reaction time on phosphorus removal

Figure 3 showed the phosphorus removal rate under different reaction time. The phosphorus removal rate increased rapidly from $0 \mathrm{~min}$ to $20 \mathrm{~min}$. The phosphorus removal rate reached $72.4 \%$ when the reaction time was $20 \mathrm{~min}$. However, the rate increased slowly when the reaction time continued to be extended. Therefore, considering the economic benefits, the optimal electrolytic time was $20 \mathrm{~min}$.

Taking both the removal rate and operating cost into consideration, the optimal conditions was $\mathrm{pH} 8.5,2 \mathrm{~g}$ lime $/ 50 \mathrm{~mL}$ wastewater, mixing rate 2.5 (equivalent units)and reaction time 20min, sedimentation time 10min. Under this condition, the removal rates of COD and TP are $52.3 \%, 50.9 \%$,respectively.

\section{B. Results of phosphorus removal by electrolysis}

The electrolytic experiment used iron-carbon electrodes. Electrolysis can both remove the phosphorous and lower the chroma by a large margin. Using the single factor experiment tto investigate the effect of different factors (including $\mathrm{pH}$, electric current, plates interval and electrolytic time) on phosphorus removal after cooling crystallization, meanwhile investigated the electrode passivation phenomenon .

1) Effect of $\mathrm{pH}$ on phosphorus removal.

$\mathrm{pH}$ determine the product of this experiment by affecting the existence and transformation of ferric hydroxide and ferrous hydroxide, so it has great influence on the phosphorus removal rate. Under the initial condition (electric current is $0.4 \mathrm{~A}$, phosphorus concentration is $5203 \mathrm{mg} / \mathrm{L}$ ), the experiment was carried out under different $\mathrm{pH}$ values $(\mathrm{pH}=5,6,7,8)$ for $30 \mathrm{~min}$. Taking the electrode passivation into consideration, we designed another group of experiment under the same conditions except that the reaction time is $10 \mathrm{~min}$ followed by $2 \mathrm{~min}$ of electrode exchanging. The result is showed in Fig.1.



Fig.4.Effect of $\mathrm{pH}$ on phosphorus removal

Figure 4 showed that when the electrodes were not exchanged, the phosphorus removal rate raised and then decreased when the $\mathrm{pH}$ continued to become higher. When the $\mathrm{pH}$ equals 7 , the phosphorus removal rate reached the peak, 29.6\%; when the $\mathrm{pH}$ was low, the phosphate removal rate was about $20 \%$, which was a very poor effect; under basic conditions, 
the phosphorus removal rate was lowered due to the production of ferric hydroxide and ferrous hydroxide; the neutrality condition was best for phosphorus removal because the concentration of ferric ion and ferrous ion were high instead of developing into ferric hydroxide precipitate or ferrous hydroxide precipitate, at the same time, the orthophosphate concentration was high to produce precipitate more easily.

White precipitate appeared on the electrode surface after the experiment was conducted for a period of time which indicated the phenomenon of electrode passivation. The electrode passivation was more serious when the $\mathrm{pH}$ was higher. After the exchanging of electrodes, the phosphorus removal rate increased by $2.6 \%, 8.3 \%, 7.2 \%, 6.5 \%$, respectively. After the electrodes exchanging, the carbon electrode was anode and the iron electrode was cathode, hydrogen was produced from the cathode and served to break the passivation layer and clean the surface of the electrode, this contributed to a higher phosphorus removal rate.

2) Effect of electric current density on phosphorus removal

The key factor whether phosphate precipitate can be produced is the concentration of ferric ion in the solution, changing the concentration of ferric ion by adjusting the electric current, the phosphorus removal rate increased when the integration rate of ferric ion and dissolved phosphate was increased. But at the same time, it increases the energy consumption of the current and the plate, so to determine the best current has a double meaning in obtaining ideal phosphorus removal rate and saving electrolytic energy consumption. Adjusting $\mathrm{pH}=7$, reaction and sedimentation time was 30min, 20 min. setting current of $0.2 \mathrm{~A}, 0.3 \mathrm{~A}, 0.4 \mathrm{~A}, 0.5 \mathrm{~A}, 0.6 \mathrm{~A}$, respectively, exchange electrode reaction $2 \mathrm{~min}$ per $12 \mathrm{~min}$. The result is showed in Figure 4.

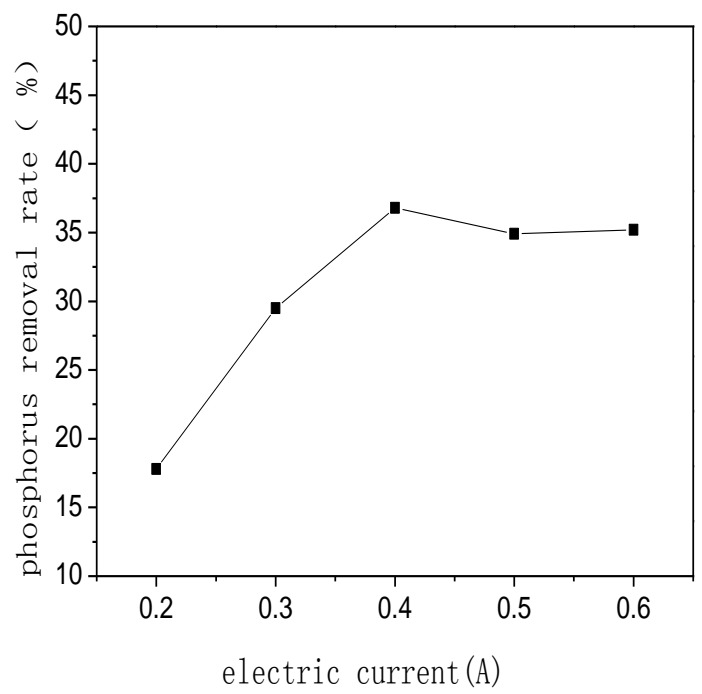

Fig.5 Effect of electric current density on phosphorus removal

Figure 5 showed that with the increase of electric current, the phosphorus removal rate increased rapidly, the removal rate reached $36.8 \%$ when the electric current was $0.4 \mathrm{~A}$. But when the electric current continued to raise, the removal rate increased very slowly, the effect of electric current on phosphorus removal was no longer significant. When the current density was lower than $0.4 \mathrm{~A}$, the system was not capable of producing enough $\mathrm{Fe}^{2+}$, so the increased current density can help increase the dissolve rate of $\mathrm{Fe}^{2+}$, the phosphorus removal rate increased as a result. When the current went on increasing, the energy consumption of phosphorus removal increased, so the optimal condition was achieved when electric current was $0.4 \mathrm{~A}$

3) Effect of electrolytic time on phosphorus removal

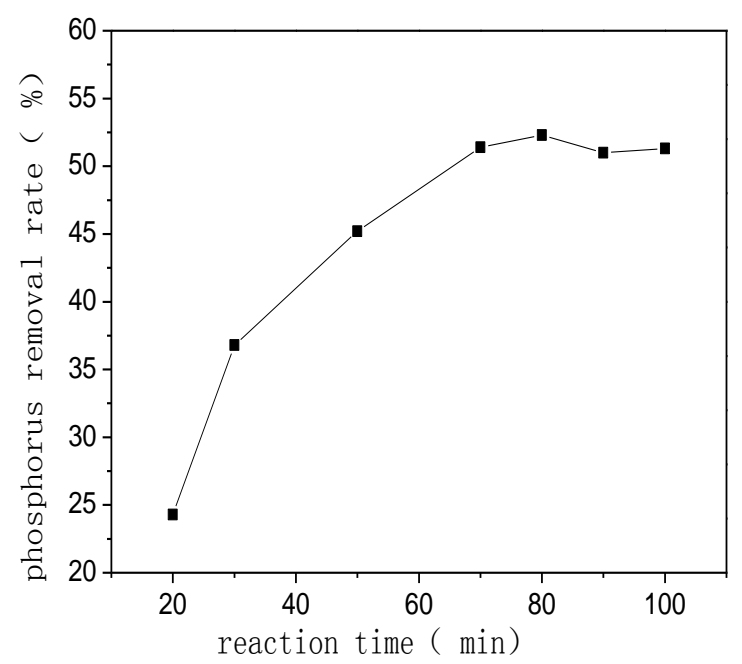

Fig.6 Effect of electrolytic time on phosphorus removal

Figure 6 showed the phosphorus removal rate under different reaction time. The phosphorus removal rate increased gradually when the electrolytic time extended. The phosphorus removal rate reached $52.3 \%$ when the electrolytic time was $80 \mathrm{~min}$, however, the rate increased slowly when the reaction time continued to be extended. Therefore, considering the economic benefits, the optimal electrolytic time was $80 \mathrm{~min}$. The electrolytic time had direct influence on the phosphorus removal rate, under the same operating conditions, the phosphorus removal rate was higher when the electrolytic time extended. This was due to the fact that when the electrolytic time was longer, the iron ion dissolved in the water sample was more, then more floc unit were produced which contributes to a better removal result. At the same time, the floatation effect was better thanks to the more tiny bubbles emerged from the cathode. When the electrolytic time was much longer, however, the electrode passivation effect was intensified and led to excessive energy consumption.

Taking both the removal rate and operating cost into consideration, the optimal conditions are $\mathrm{pH} 7$, electric current $0.4 \mathrm{~A}$, reaction time $80 \mathrm{~min}$, exchange electrode reaction $2 \mathrm{~min}$ 
per $12 \mathrm{~min}$. Under this condition, the removal rates of COD and TP are $52.3 \%, 50.9 \%$,respectively.

\section{CONCLUSIONS}

The results indicated that the optimal conditions are: lime dosage was $2 \mathrm{~g}$, $\mathrm{pH} 8.5$, mixing rate 2.5 (equivalent units)and reac tion time $20 \mathrm{~min}$, sedimentation time $10 \mathrm{~min}$; using the soluble iro $\mathrm{n}$ plate and carbon rod as electrode plate, electrolysis $\mathrm{pH} 7$, ele ctric current $0.4 \mathrm{~A}$, reaction time $80 \mathrm{~min}$, exchange electrode re action $2 \mathrm{~min}$ per $12 \mathrm{~min}$.

The experimental results show that the removal rates of $\mathrm{CO}$ $\mathrm{D}$ and TP are $86.4 \%, 69.9 \%$,respectively. TP decreased from 18 $256 \mathrm{mg} / \mathrm{L}$ to $2482 \mathrm{mg} / \mathrm{L}$.COD decreased from $255218 \mathrm{mg} / \mathrm{L}$ to 76 $816 \mathrm{mg} / \mathrm{L}$.

Lime- electrolysis was developed to treat the Ultra-high conc entration phosphorus-containing Wastewater, the combined proce ss not only can effectively remove TP, but also improve water bi odegradability which is conducive to the subsequent process.

\section{ACKNOWLEDGMENT}

This project is supported by Major national science and technology projects (2013ZX07201007).

\section{REFERENCES}

[1] Jikui Lan, Panyong Zhang. "Research on the chemical precipitation treatment of wastewater containing ultra-high concentration of phosphorus". Industrial Water Treatment, Tianjin, vol. 31, pp58-60, Jan 2011.

[2] Peishi Qi, Zhanli Chen, Huanxin Zhang, et al. Pretreatment of high-strength unbiodegradable dye wastewater with electrolysis processes. Journal Of Harbin Institute Technology, Harbin, vol. 41, pp.47-51, Oct 2009.

[3] SAHSET I, YALCIN SY, VAHDETTIN T. Optmization of phosphate retrodes. Separation and Purification Technology, Amaterdam, vol. 52, pp. 394-401,Feb 2006.

[4] SAHSET I,NUHID, YALCIN SY. The effects of $\mathrm{pH}$ on phosphate removal from wastewater by electrocoagulation with iron plate electrodes. Journal of Hazardous Materials, Holland, vol. 137, pp. 1231-1235, Feb, 2006.

[5] CISNEROS $\mathrm{R}$ L, ESPINOZA A G, LITTER MI. Photo degradation of an azo dye of the textile industry. Chemosphere, England, vol. 48, pp. 393-399, Apr, 2002.

[6] Chong Lin, $\mathrm{Na} \mathrm{Li,} \mathrm{Kuang} \mathrm{qiong} \mathrm{Ke,et} \mathrm{al.} \mathrm{Recovery} \mathrm{of} \mathrm{phosphorus}$ from pharmaceutical industry wastewater with composite calcium. CIESC Journal, Beijin, vol. 60,pp. 2346-2350, Sep, 2009. 